\title{
AVALIAÇÃO DA CONFORMIDADE LEGAL EM RELAÇÃO AS NORMAS REGULAMENTADORAS DO MINISTÉRIO DO TRABALHO E EMPREGO: UM ESTUDO DE CASO
}

\author{
Marcelo de Jesus Rodrigues da Nóbrega \\ Pós-Doutor em Engenharia Civil (UERJ) \\ Professor da UNIGAMA, CEFET-RJ e Universidade Santa Úrsula. engmarcelocefet@terra.com.br
}

Fabiano Battemarco da Silva Martins

Mestrado Acadêmico em Engenharia Agrícola e Ambiental pela

Universidade Federal Rural do Rio de Janeiro, RJ, BRASIL

Graduado em Engenharia Civil, UNISUAM, Rio de Janeiro, RJ, Brasil

fabianobattemarco@gmail.com

Michele Soares Rodrigues Raed

Graduada em Engenharia Civil, UNISUAM, Rio de Janeiro, RJ, Brasil

chelisoares2010@gmail.com

\section{Resumo}

O presente artigo abordas as não conformidades às Normas Regulamentadoras do Ministério do Trabalho e Emprego (MTE), principalmente as NR's 5 e 6 nas atividades desenvolvidas pela empresa MR Engenharia nas suas próprias instalações e nos locais das contratantes. A partir da verificação das atividades executadas, coleta de dados, fotos e entrevistas com os funcionários responsáveis, realizou-se uma revisão do atendimento às NR's pertinentes ao escopo de trabalho da empresa. Este trabalho realizou o cálculo das penalidades e multas relativas às não conformidades identificadas, visando à integridade física e a saúde das pessoas envolvidas nas atividades da empresa, bem como a preservação do seu patrimônio.

Palavras-chave: Conformidade, Normas Regulamentadoras, Segurança.

\section{ASSESSMENT OF LEGAL CONFORMITY IN RELATION TO THE REGULATORY STANDARDS OF THE MINISTRY OF LABOR AND EMPLOYMENT: A CASE STUDY}

\begin{abstract}
This article draws attention to noncompliance with regulatory standards of the Ministry of Labor and Employment (MTE), especially NR's 5 and 6 in the activities developed by the company MR Engineering in their own facilities and at the sites of contractors. From the verification of the activities performed, data collection, photos and interviews with the responsible officials, there was a review of compliance with NRs relevant to the company's scope of work. This work carried out the calculation of penalties and fines relating to the non-compliances identified, for the physical integrity and health of the people involved in the company's activities as well as the preservation of their heritage.
\end{abstract}

Keywords: Compliance, Standards Regulatory, Security. 


\section{INTRODUÇÃO}

A Engenharia Civil trabalha com diversas áreas do conhecimento e recentemente as questões de Segurança e Saúde do Trabalho. Atualmente vem ganhando papel relevante, face às normas regulamentadoras (NR's) do Ministério do Trabalho e Emprego (MTE) serem mais frequentemente atualizadas e rigorosas. Desta forma, as não conformidades permitem gerar penalidades para o empregador, além de outras consequências. Tais como: processos criminais, civis, administrativos e dentre outras.

Na prática de trabalho, observa-se que o ramo de prestação de serviços de manutenção de espaços públicos é constantemente negligenciado na área de segurança e saúde ocupacional devido à falsa impressão de que os riscos observados nesta atividade são menores do que outros ramos da indústria e serviço. Isto ocorre, sobretudo, devido à aparente simplicidade de algumas atividades, tais como: trocas de luminárias, tetos e revestimentos.

Muitas vezes algumas atividades que na compreensão de grande parte da população e dos governantes são atividades e que aparentemente não apresentariam quaisquer riscos, são negligenciadas. Todavia, estes trabalhos podem acarretar diversos riscos, tais como: risco de queda, choque elétrico acidental e queda de materiais sobre pessoas.

Sendo assim, objetivou-se com esta pesquisa, avaliar as atividades desenvolvidas pela empresa MR Engenharia, com a finalidade de identificar as não conformidades de algumas Normas Regulamentadoras do MTE, visando à integridade física e a saúde das pessoas envolvidas nas atividades realizadas, além de preservar o patrimônio da empresa.

\section{DESENVOLVIMENTO}

\subsection{Revisão de Literatura}

2.1.1 Descrição da empresa.

Fundada em 1991, a MR Engenharia (nome fictício) é uma empresa no desenvolvimento e implantação de serviços em sistemas elétricos com alta eficiência em edificações industriais e comerciais. A empresa executa: laudo técnico de auditoria em instalações elétricas; auditorias de eficiência energética; projetos de instalação elétrica de baixa tensão, média e alta tensão; projetos de luminotécnica; instalação de grupos geradores, operação e manutenção destes equipamentos; execução de projeto, montagem e inspeção de SPDA; projetos de instalações especiais e serviços de montagens de instalações elétricas. 
A sede da empresa está localizada no centro da cidade do Rio de Janeiro. A área para execução dos serviços de campo se localiza no município de Nilópolis (RJ) e nas instalações das empresas contratantes. Os canteiros de obras montados pela empresa buscam atender as determinações das empresas contratantes e as determinações das referências legais.

No caso da MR Engenharia, deve-se ainda levar em consideração a ausência de estabilidade no emprego dos profissionais. Em muitos casos, o tempo de duração do emprego corresponde à duração da execução da obra, gerando alta rotatividade dos funcionários de uma obra para outra, dificultando a adaptação, capacitação e treinamento destes funcionários.

Em função desta rotatividade de funcionários, as versões mais recentes das normas do Ministério do Trabalho e Emprego (MTE) determinam a necessidade de implementação de programas de treinamentos com reciclagens associadas à troca de função e a mudança de empresa, devido a diferentes tipos de contratos.

A monografia foi realizada buscando conhecer, entender e verificar a adequação das Normas Regulamentadoras (NR's) nas atividades desenvolvidas pela MR Engenharia nas suas instalações e nas atividades executadas nos locais de seus contratantes. Também serão avaliadas as multas referentes aos itens de não conformidade e os valores aplicáveis.

As ocorrências de não conformidades foram relacionadas no plano de ação e sugeridas as suas adequações. A solução indicada pode ter como referência as normas da ABNT e as determinações do MTE e outras referências técnicas. Caso não exista uma referência nacional, ou na ausência ou omissão destas, os padrões internacionais serão utilizados para a não conformidade evidenciada.

\subsubsection{Conformidade com as normas regulamentadoras.}

Durante a execução deste trabalho, verificou-se que a direção da MR Engenharia tem como objetivo atender as determinações da legislação para atender as exigências contratuais de seus principais contratantes, para reduzir o risco de geração de passivo trabalhista e criar um diferencial de mercado. $\mathrm{O}$ atendimento a legislação trabalhista apenas por necessidades contratuais não é uma forma aceitável de gestão de uma empresa.

A base de análise das medidas de segurança terá como base o atendimento das Normas Regulamentadoras (NR's) que explicitam as determinações contidas nos artigos 154 a 201 da CLT, que são parâmetros técnicos para pessoas ou empresas, que devem também atender o pactuado nas Convenções e nos Acordos Coletivos de Trabalho de cada categoria e nas Convenções Coletivas 
sobre Prevenção de Acidentes. As NRs são interdependentes e este trabalho objetiva verificar seu atendimento por parte da empresa analisada.

A necessidade de atendimento de toda a legislação trabalhista é definida na CLT e pela NR 1, item 1.1. Neste item, entende-se que tais Normas Regulamentadoras - NR, relativas à Segurança e Medicina do Trabalho, são de observância obrigatória pelas empresas privadas e públicas e pelos órgãos públicos da administração direta e indireta, bem como pelos órgãos dos Poderes Legislativo e Judiciário, que possuam empregados regidos pela Consolidação das Leis do Trabalho - CLT.A obediência às Normas Regulamentadoras é de responsabilidade das empresas contratantes e contratadas, conforme determinação do item 1.6.1 da NR 1. A decisão de atender as determinações das Normas Regulamentadoras não pode ser encarada como um diferencial de mercado, mas como o mínimo exigido de qualquer organização.

A empresa possui grande exigência nas questões de saúde ocupacional e segurança do trabalho por parte das suas contratantes, pois, a empresa tomadora de serviço é obrigada a fiscalizar a empresa prestadora de serviços para que não se configure relação de responsabilidade subsidiária, conforme é determinado pelo item IV da Súmula $n^{\circ} 331$ do TST.

Esse item estabelece que o inadimplemento das obrigações trabalhistas, por parte do empregador, implica a responsabilidade subsidiária do tomador dos serviços, quanto àquelas obrigações. As exigências de grandes empresas no que ser refere à segurança demandam um esforço administrativo e técnico que vai necessitar que a empresa investisse em instalações, em mão de obras e melhoria profunda nos padrões da organização. Assim, para a MR Engenharia, a melhoria nas condições de trabalho é um diferencial de mercado que pode ser útil na conquista de novos contratos com grandes empresas. Desta maneira, a escolha da direção da empresa por esta política se deve a possibilidade de alcançar e conquistar clientes mais rentáveis.

A existência de certificações na área de qualidade também é um fator importante para o atendimento das determinações de segurança. A organização de segurança do trabalho em uma empresa necessita de uma gestão eficiente de processo e de documentos para que o resultado atenda as expectativas da organização.

Para a empresa seguir com as implementações da NBR ISO 9001:2008 e a OHSAS18001: 2007, ela precisa e contratar funcionários para ficar à frente do Setor de Segurança e Gestão. Com isso, irá melhorar o atendimento aos padrões de organização definidos na NBR ISO 9001:2008 é a base para o atendimento de uma futura certificação na NBR ISO 14001:2004 e na OHSAS 18001:2007. 
Este capítulo apresenta a análise da NR 5, NR 6 que são comuns a todas as empresas que mantém empregados contratados através da CLT.

\subsubsection{NR 5 - Comissão Interna de Prevenção de Acidentes - CIPA}

Conforme determinação da NR 5, todas as empresas privadas, públicas, sociedades de economia mista, instituições beneficentes, cooperativas, os clubes, que possuam empregados regidos pela $\mathrm{CLT}$, dependendo do grau de risco da empresa e do número mínimo de 20 (vinte) empregados, deverão constituir e manter a Comissão Interna de Prevenção de Acidentes (CIPA),

A NR 5 possui 3 (três) quadros para determinação do dimensionamento da CIPA. Com o Quadro I, através do CNAE, verifica-se o Grupo em que a MR Engenharia está classificada; através do Quadro II e do Quadro III verifica-se o agrupamento para o dimensionamento da CIPA.

A Tabela 1 apresenta o grupo da MR Engenharia determinado através do seu código CNAE, conforme o Quadro III na NR 5. Através do Quadro II desta mesma NR, verifica-se que o grupo correspondente, c-18, corresponde ao grupo denominado "Construção".

Tabela 1 - Código CNAE.

\begin{tabular}{lll}
\hline CNAE & Descrição & Grupo \\
\hline $43.21-5$ & Instalações Elétricas & C-18 \\
\hline
\end{tabular}

Fonte: (NR 5).

O dimensionamento da CIPA é dado pelo número de empregados e pelo grupo de classificação da empresa através do Quadro I da NR 5. Como a empresa possui 59 empregados, verifica-se na Figura 1 que há a necessidade de constituir CIPA com dois membros suplentes e dois efetivos. Como a CIPA deve ser paritária, deverá ser composta por mais 4 (quatro) elementos, totalizando 8 (oito) pessoas.

Figura 1 - Quantificação da formação da CIPA da MR.

\begin{tabular}{|c|c|c|c|c|c|c|c|c|c|c|c|c|c|c|c|}
\hline 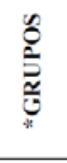 & $\begin{array}{c}\mathrm{N}^{\circ} \text { de } \\
\text { Empregados no } \\
\text { Estabelecimento } \\
\mathrm{N}^{\circ} \text { de Membros } \\
\text { da CIPA }\end{array}$ & $\begin{array}{c}0 \\
a \\
19\end{array}$ & $\begin{array}{c}20 \\
\text { a } \\
29\end{array}$ & $\begin{array}{c}30 \\
a \\
50\end{array}$ & $\begin{array}{c}51 \\
\mathrm{a} \\
80\end{array}$ & $\begin{array}{c}81 \\
a \\
100\end{array}$ & $\begin{array}{c}101 \\
a \\
120\end{array}$ & $\begin{array}{c}121 \\
a \\
140\end{array}$ & $\begin{array}{c}141 \\
a \\
300\end{array}$ & $\begin{array}{c}301 \\
a \\
500\end{array}$ & $\begin{array}{c}501 \\
a \\
1000\end{array}$ & $\begin{array}{c}1001 \\
a \\
2500\end{array}$ & $\begin{array}{c}2501 \\
\text { a } \\
5000\end{array}$ & $\begin{array}{c}5001 \\
a \\
10.000\end{array}$ & $\begin{array}{c}\text { Acima de } \\
10.000 \text { para } \\
\text { cada grupo de } \\
2.500 \\
\text { acrescentar }\end{array}$ \\
\hline \multirow[t]{2}{*}{ C-18 } & Efetivos & & & & 2 & 2 & 4 & 4 & 4 & 4 & 6 & 8 & 10 & 12 & 2 \\
\hline & Suplentes & & & & 2 & 2 & 3 & 3 & 3 & 4 & 5 & 7 & 8 & 10 & 2 \\
\hline
\end{tabular}

Fonte: (NR 4).

Por não haver a formação da CIPA na sede da MR Engenharia e nos contratos que são executados, a empresa encontra-se em não conformidade em relação ao atendimento da NR 5 , 
referente ao item $5.2^{1}$ e nos demais itens desta NR. Além disso, pelo fato de a empresa possuir em alguns contratos menos de 50 funcionários em sua frente de trabalho, também se encontra em não conformidade com os itens $18.33 .1^{2}$ e $18.33 .2^{3}$ da NR 18.

A MR Engenharia atende parcialmente algumas das determinações do item 5.16 da NR 5, uma vez que a empresa possui mapas de risco, apresentados na Figura 2. Estes mapas não foram elaborados pela CIPA e correspondem às instalações administrativas (escritório) e do galpão da empresa.

Figura 2 - Mapa de risco.

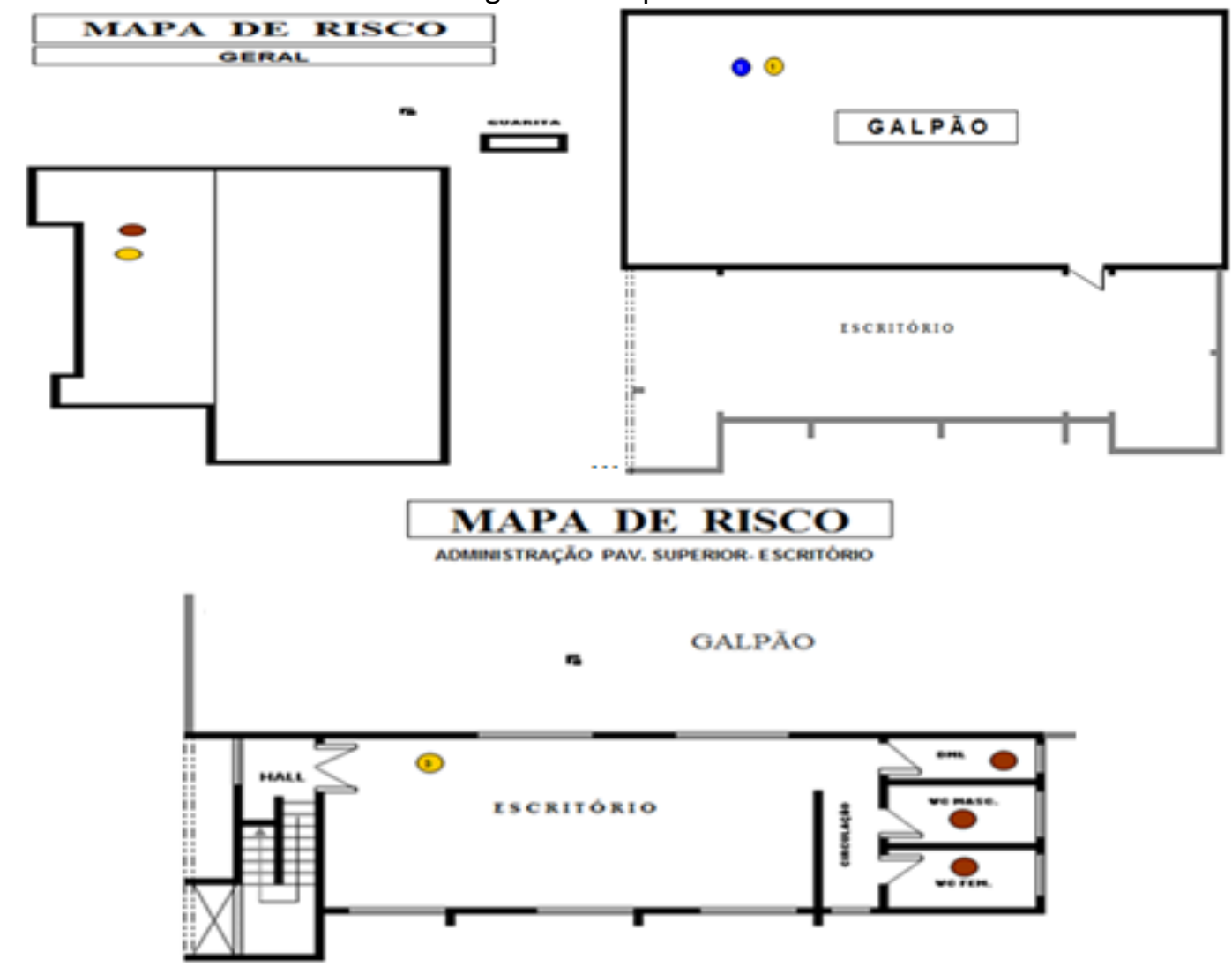

Fonte: (MR Engenharia, 2014).

Esses documentos foram elaborados por um dos técnicos de segurança devido a uma exigência de um dos contratantes. A Figura 3 apresenta uma codificação de referência para os riscos

\footnotetext{
${ }^{1} 5.2$ Devem constituir CIPA, por estabelecimento, e mantê-la em regular funcionamento as empresas privadas, públicas, sociedades de economia mista, órgãos da administração direta e indireta, instituições beneficentes, associações recreativas, cooperativas, bem como outras instituições que admitam trabalhadores como empregados.

${ }^{2}$ 18.33.1 A empresa que possuir na mesma cidade 1 (um) ou mais canteiros de obra ou frentes de trabalho, com menos de 70 (setenta) empregados, deve organizar CIPA centralizada.

${ }^{3}$ 18.33.2 A CIPA centralizada será composta de representantes do empregador e dos empregados, devendo ter pelo menos 1 (um) representante titular e 1 (um) suplente, por grupo de até 50 (cinquenta) empregados em cada canteiro de obra ou frente de trabalho, respeitando-se a paridade prevista na NR 5.
} 
ambientais, com a finalidade de facilitar a compreensão do mapa de risco. Sendo que, o mapa de risco apresentado pelo técnico está muito confuso, não está muito explícito o grau de risco do local averiguado.

Recomenda-se a elaboração de um novo mapa de risco para facilitar a visualização dos riscos encontrados no escritório e no galpão da empresa em estudo. O novo mapa de risco deverá apresentar todos os riscos identificados no PPRA da empresa.

Figura 3 - Classificação dos riscos ambientais.

\begin{tabular}{|c|c|c|c|c|c|}
\hline $\begin{array}{l}\text { GRUPO I: } \\
\text { VERDE }\end{array}$ & $\begin{array}{l}\text { GRUPO II: } \\
\text { VERMELHO }\end{array}$ & $\begin{array}{l}\text { GRUPO III: } \\
\text { MARROM }\end{array}$ & $\begin{array}{l}\text { GRUPO IV: } \\
\text { AMARELO }\end{array}$ & $\begin{array}{l}\text { GRUPO V: } \\
\text { Azul }\end{array}$ & \multirow{11}{*}{ IECENDA: } \\
\hline Riscos Físicos & Riscos Quimicos & Riscos Biológicos & Riscos Ergonômicos & Riscos de Acidentes & \\
\hline Ruidos & Poeiras & Virus & $\begin{array}{l}\text { Esforço fisico } \\
\text { intenso }\end{array}$ & $\begin{array}{l}\text { Arranjo fisico } \\
\text { inadequado }\end{array}$ & \\
\hline Vibrações & Fumos & Bactérias & $\begin{array}{c}\text { Levantamento e } \\
\text { transporte manual } \\
\text { de peso }\end{array}$ & $\begin{array}{l}\text { Máquinas e } \\
\text { equipamentos } \\
\text { sem proteçăo }\end{array}$ & \\
\hline $\begin{array}{l}\text { Radiaçōes } \\
\text { ionizantes }\end{array}$ & Neblinas & Protozoários & $\begin{array}{l}\text { Exigência de } \\
\text { postura inadequada }\end{array}$ & $\begin{array}{c}\text { Ferramentas } \\
\text { inadequadas ou } \\
\text { defeituosas }\end{array}$ & \\
\hline $\begin{array}{l}\text { Radiações não- } \\
\text { ionizantes }\end{array}$ & Neblinas & Fungos & $\begin{array}{l}\text { Controle rígido } \\
\text { de produtividade }\end{array}$ & $\begin{array}{l}\text { lluminação } \\
\text { inadequada }\end{array}$ & \\
\hline Frio & Gases & Parasitas & $\begin{array}{c}\text { Imposição de } \\
\text { ritmos excessivos }\end{array}$ & Eletricidade & \\
\hline Calor & Vapores & Bacilos & $\begin{array}{l}\text { Trabalhos em turnos } \\
\text { diurno e noturno }\end{array}$ & $\begin{array}{l}\text { Probabilidade } \\
\text { de incêndio } \\
\text { ou exposão }\end{array}$ & \\
\hline $\begin{array}{l}\text { Pressões } \\
\text { anormais }\end{array}$ & $\begin{array}{l}\text { Substândias, } \\
\text { cmpostos ou } \\
\text { produtos químicos } \\
\text { em geral }\end{array}$ & - & $\begin{array}{l}\text { Jornada de trabalho } \\
\text { prolongada }\end{array}$ & $\begin{array}{l}\text { Armazenamento } \\
\text { inadequado }\end{array}$ & \\
\hline Umidade & - & - & $\begin{array}{l}\text { Monotonia e } \\
\text { repettivividade }\end{array}$ & $\begin{array}{c}\text { Animais } \\
\text { peçonhentos }\end{array}$ & \\
\hline - & - & - & $\begin{array}{l}\text { Outras situações } \\
\text { causadoras de } \\
\text { estresse fisico } \\
\text { e/ou psiquico }\end{array}$ & $\begin{array}{l}\text { Outras situações } \\
\text { de risco que } \\
\text { poderão contribuir } \\
\text { para a ocorrência } \\
\text { de acidentes }\end{array}$ & \\
\hline
\end{tabular}

Fonte: (Dicas de Prevenção de Acidentes e Doenças no Trabalho, 2005).

Recomenda-se que a MR Engenharia melhore o mapa de risco como um todo e aprimore a visualização dos riscos apresentados. Nos documentos existentes não são apresentados os ricos em todos os ambientes da empresa e não se apresenta uma legenda clara. Também se sugere que sejam elaborados mapas de risco para todas as áreas em que atua inclusive em locais externos à empresa.

Em entrevista aos funcionários, evidenciou-se que o atendimento das determinações da NR 5 somente é realizado quando há exigência do contratante. Devido a esta condição e o caráter precário dos mapas de riscos considerou-se que a empresa não atende a NR 5 em sua totalidade, o que impactará no cálculo de multas realizado no Capítulo 4. 
Recomenda-se que a empresa constitua a CIPA através de eleição e viabilize o seu funcionamento, conforme determinação do item os itens $5.7^{4}, 5.8^{5}, 5.9^{6}$ da NR 5. A empresa deverá treinar os funcionários que farão parte da CIPA, conforme os itens 5.32, 5.32.1, e 5.32.2 NR 5.

Este treinamento deverá ser direcionado para titulares e suplentes em, no máximo, 30 dias antes da posse. $\mathrm{O}$ treinamento a ser oferecido deverá ter carga horária de vinte horas, distribuídas em no máximo oito horas diárias durante o expediente normal da empresa.

A CIPA deverá participar da investigação de acidentes da empresa, apoiar a elaboração do mapa de riscos e identificar situações no ambiente de trabalho que possam trazer riscos ao trabalhador. A CIPA deverá promover com os técnicos de segurança da empresa a Semana Interna de Prevenção de Acidentes do Trabalho (SIPAT).

\subsubsection{NR 6 - Equipamentos de Proteção Individual - EPI}

De acordo com a NR 6, as empresas são obrigadas a fornecer gratuitamente aos seus empregados Equipamentos de Proteção Individual (EPI) adequados aos riscos de exposição, destinados a proteger a saúde e a integridade física do trabalhador. Todo equipamento utilizado deve ter o Certificado de Aprovação (CA) emitido pelo MTE.

A MR Engenharia se encontra em conformidade com o item 6.5.17 desta NR. Mesmo sendo desobrigada a constituir SESMT, a MR Engenharia optou pela contratação de 2 (dois) técnicos de segurança para que estes possam desenvolver e fiscalizar as medidas de segurança necessárias aos contratos com seus clientes e ao fornecimento de EPI aos funcionários.

Verificou-se que todos os EPI disponibilizados pela empresa apresentavam CA válidos, atendendo os itens 6.6.1c, 6.2, 6.9.1 e o 6.9.3. Além disso, também foi evidenciado que a empresa fornece EPI em perfeito estado de conservação e funcionamento, atendendo o disposto no item 6.3 da NR 6.

A definição dos EPI, ou seja, o atendimento do item 6.6.1, alínea "a" é realizada por contrato e não por especificação da empresa. Os profissionais que são lotados na sede possuem um conjunto básico de EPI, composto de capacete de segurança de aba frontal e bota de segurança com biqueira

\footnotetext{
${ }^{4} 5.7$ O mandato dos membros eleitos da CIPA terá a duração de um ano, permitida uma reeleição.

${ }^{5} 5.8$ É vedada a dispensa arbitrária ou sem justa causa do empregado eleito para cargo de direção de Comissões Internas de Prevenção de Acidentes desde o registro de sua candidatura até um ano após o final de seu mandato.

${ }^{6} 5.9$ Serão garantidas aos membros da CIPA condições que não descaracterizem suas atividades normais na empresa, sendo vedada a transferência para outro estabelecimento sem a sua anuência, ressalvado o disposto nos parágrafos primeiro e segundo do artigo 469, da CLT.

7 6.5.1 Nas empresas desobrigadas a constituir SESMT, cabe ao empregador selecionar o EPI adequado ao risco, mediante orientação de profissional tecnicamente habilitado, ouvida a CIPA ou, na falta desta, o designado e trabalhadores usuários. (Alterado pela Portaria SIT n.o 194 , de 07 de dezembro de 2010).
} 
não metálica, que são utilizados nas visitas a clientes com fins de licitação e prestar apoio técnico. Destaca-se que quando os funcionários estão no galpão utilizam apenas o uniforme da empresa.

Nos contratos onde não há essa exigência a empresa analisada costuma reaproveitar os EPI que foram utilizados em outros contratos, sem, contudo, realizar a especificação por conta das características do serviço, tanto as características elétricas quanto aos riscos adicionais.

Verificou-se ainda que a empresa apenas tenha o uso do EPI fiscalizado nos locais de trabalho das contratantes, caracterizando descumprimento do item 6.6.1b. Os EPI são substituídos quando danificados ou extraviados, atendendo o item 6.6.1e, porém a empresa não se responsabiliza pela higienização e manutenção periódica; descumprindo o item 6.6.1f.

O fornecimento de EPI deve ser acompanhado de treinamento quanto a sua utilização, conforme determina o item 6.6.1, alínea " $\mathrm{d}$ "8. Verificou-se que a empresa não realiza treinamento quanto à utilização, guarda conservação e limpeza dos EPI, descumprindo este item. Não existe nenhuma evidência de formulário ou qualquer outro meio de registro da entrega de EPI na maioria dos serviços realizados pela MR Engenharia, caracterizando descumprimento do item 6.6.1h. O registro somente é realizado quando esta documentação é exigida pelo cliente. Na Figura 4 é apresentado um modelo de ficha de controle de EPI, que pode ser utilizado como referência para a empresa.

Recomenda-se que os técnicos de segurança da empresa elaborem a ficha de controle e entrega de EPI's, bem como ofereçam e registrem o treinamento sobre seu uso, guarda e conservação para todos os funcionários da empresa em seus contratos. O uso dos EPI's deverá ser fiscalizado por estes profissionais nas instalações da MR Engenharia para assegurar melhor o desempenho dos funcionários quanto ao uso e reduzir os riscos existes no ambiente de trabalho.

Os EPI's previstos no Anexo I da NR 6 que são utilizados pelo funcionário responsável pelo serviço de conservação e limpeza são: Luvas para proteção contra umidade proveniente de operações com uso de água e calçado para proteção dos pés e pernas contra umidade proveniente de operações com uso de água.

Os EPI para uso em serviços com eletricidade são prescritos no Anexo I da NR 6. Contudo, destaca-se ainda que para todos os funcionários a empresa não se encontra em conformidade com o Anexo I, letra H desta NR.

\footnotetext{
${ }^{8}$ 6.6.1 Cabe ao empregador quanto ao EPI: a) adquirir o adequado ao risco de cada atividade;

b) exigir seu uso; c) fornecer ao trabalhador somente o aprovado pelo órgão nacional competente em matéria de segurança e saúde no trabalho; d) orientar e treinar o trabalhador sobre o uso adequado guarda e conservação; e) substituir imediatamente, quando danificado ou extraviado; f) responsabilizar-se pela higienização e manutenção periódica; e,g) comunicar ao MTE qualquer irregularidade observada, h) registrar o seu fornecimento ao trabalhador, podendo ser adotados livros, fichas ou sistema eletrônico.
} 
Figura 4 - Ficha de controle de entrega de EPI

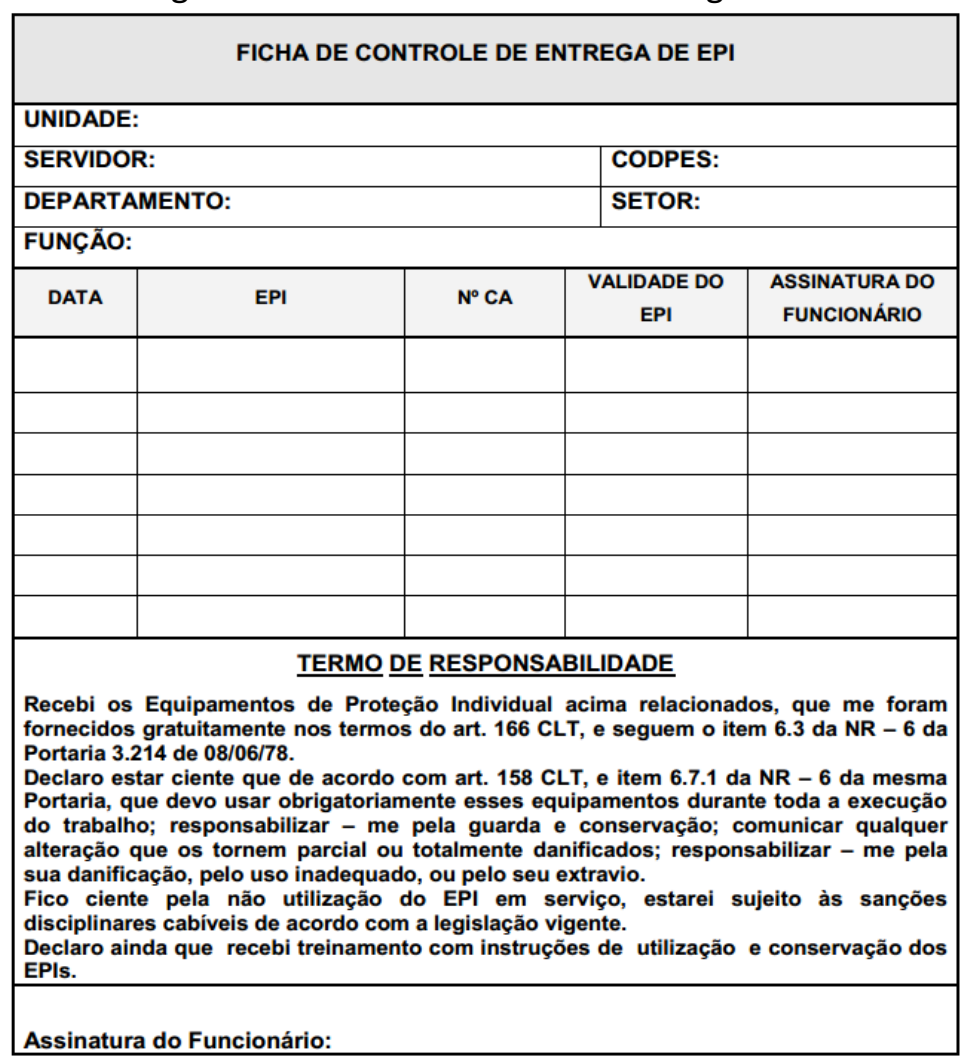

Fonte: (USP, 2010).

A empresa não possui ou fornece macacão adequado para cada frente de trabalho. Durante as visitas realizadas, verificou-se que os funcionários da empresa recebem um único modelo de vestimenta para qualquer tarefa que seja realizada, como pode ser observado na Figura 5.

Esta não conformidade é particularmente grave para os eletricistas e ajudantes de eletricistas que deveriam receber vestimenta condutiva para proteção de todo o corpo contrachoques elétricos.

Figura 5 - Vestimenta para proteção do corpo inteiro.

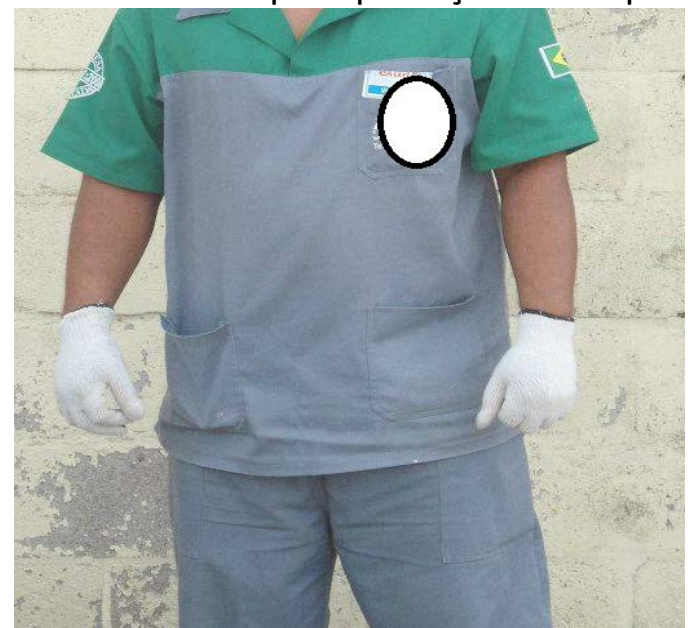

Fonte: (Elaborado pelo autor, 2020). 
Sugere-se que a empresa promova Diálogos Diários de Segurança (DDS) com informações relativas ao uso dos EPI. Sugere-se que os seguintes temas sejam abordados: uso do EPI Indicado apenas para as finalidades a que se destina; iniciar o serviço apenas com o uso dos EPI indicados para a tarefa a realizar; responsabilização pela guarda e conservação dos EPI; comunicação de danos ou extravio nos EPI; informar que a recusa em não usar os EPI implica em punição prevista em lei (Artigo 482 da CLT); proibição de alterar o padrão dos EPI; inutilização por procedimento inadequado; e necessidade de devolução do EPI em caso de desligamento.

\subsection{Metodologia}

Através do objetivo do presente estudo que tem como finalidade avaliar as atividades desenvolvidas pela empresa MR Engenharia, com a finalidade de identificar as não conformidades de algumas Normas Regulamentadoras do MTE, visando à integridade física e a saúde das pessoas envolvidas nas atividades realizadas, além de preservar o patrimônio da empresa.

O meio de investigação escolhido para tal artigo foi de caráter bibliográfico, que se baseia em estudos já realizados ao estudar artigos, trabalhos de conclusão de cursos, leis, entre outros, esse meio investigativo juntamente com os métodos escolhidos foi de total importância para uma melhor compreensão do caso abordado no presente artigo.

Por meio de uma abordagem qualitativa, tornou-se possível enxergar e interpretar as informações que foram reveladas por meio dos dados nas respectivas tabelas.

Esta pesquisa apresenta características de uma pesquisa bibliográfica, haja vista que foi necessária a realização de frequentes leituras existentes na literatura para fornecer embasamento teórico ao estudo. Utilizou-se de pesquisa quantitativa para mensurar os dados que compõem os gráficos com os resultados encontrados. Por meio de uma abordagem qualitativa, tornou-se possível enxergar e interpretar as informações que foram reveladas por meio dos dados nas respectivas tabelas.

A presente pesquisa foi classificada como exploratória. De acordo com Gil (2008, p. 41), “o objetivo da pesquisa exploratória é proporcionar maior familiaridade com o problema, com vistas a torná-lo mais explícito ou a constituir hipóteses, que deem sustentação ao objetivo central do estudo". Referindo-se aos resultados, pode-se classificar como aplicada, já que o resultado encontrado pode contribuir para mudanças na realidade existente com a utilização de práticas normativas pela empresa estudada. 


\subsection{Estudo de Caso}

Nesta etapa do trabalho, onde a situação de saúde e segurança relativas às atividades desempenhadas na MR Engenharia foi analisada, será estimado o valor associado às multas aplicadas através da NR 28 em uma eventual vistoria do MTE. Esta ação tem por finalidade prever qual é o valor financeiro correspondente às não conformidades encontradas, com a finalidade de estimular sua adequação conforme a Tabela 3.

Tabela 2 - Penalidades e multas

\begin{tabular}{|c|c|c|c|c|c|}
\hline \multicolumn{6}{|c|}{ TABELA DE PENALIDADES } \\
\hline$N^{\circ}$ DAS NR's & ITENS & INFRAÇÃO & $N^{\circ}$ DAS NR's & ITENS & INFRAÇÃO \\
\hline 1 & 1.7 alínea $B$ & 1 & 5 & 5.40 "c" & 3 \\
\hline 5 & 5.2 & 4 & 5 & 5.40 "d" & 3 \\
\hline 5 & 5.6 & 3 & 5 & 5.40 "e" & 2 \\
\hline 5 & 5.6 .2 & 3 & 5 & 5.40 "f" & 2 \\
\hline 5 & 5.6 .4 & 2 & 5 & 5.40 "g" & 2 \\
\hline 5 & 5.7 & 2 & 5 & 5.40 "h" & 2 \\
\hline 5 & 5.8 & 3 & 5 & 5.40 "j" & 2 \\
\hline 5 & 5.9 & 3 & 5 & 5.41 & 1 \\
\hline 5 & 5.10 & 1 & 5 & 5.42 .2 & 2 \\
\hline 5 & 5.11 & 2 & 5 & 5.42 .3 & 2 \\
\hline 5 & 5.12 & 1 & 5 & 5.43 & 3 \\
\hline 5 & 5.13 & 1 & 5 & 5.45 & 2 \\
\hline 5 & 5.14 & 1 & 5 & 5.48 & 1 \\
\hline 5 & 5.14 .1 & 2 & 5 & 5.49 & 3 \\
\hline 5 & 5.14 .2 & 2 & 5 & 5.50 & 3 \\
\hline 5 & 5.15 & 3 & 6 & 6.6 .1 & 3 \\
\hline 5 & 5.17 & 2 & 6 & $6.6 .1 \mathrm{a}$ & 2 \\
\hline 5 & 5.23 & 3 & 6 & $6.6 .1 \mathrm{~b}$ & 2 \\
\hline 5 & 5.24 & 2 & 6 & $6.6 .1 \mathrm{c}$ & 2 \\
\hline 5 & 5.25 & 1 & 18 & $18 . .3 .2$ & 2 \\
\hline 5 & 5.26 & 1 & 35 & $35.3 .2(\mathrm{~A}$ a $\mathrm{D})$ & 3 \\
\hline 5 & 5.27 & 3 & 35 & 35.3 .6 & 3 \\
\hline 5 & 5.30 & 1 & 35 & 35.3 .7 .1 & 2 \\
\hline 5 & 5.31 & 2 & 35 & 35.3 .8 & 2 \\
\hline 5 & 5.31 .1 & 1 & 35 & 35.5 .2 & 4 \\
\hline 5 & 5.31 .3 & 2 & 35 & 35.4.5.1 "a" & 3 \\
\hline 5 & 5.31 .3 .1 & 2 & 35 & 35.4.5.1 "b" & 3 \\
\hline 5 & 5.32 & 3 & 35 & 35.4.5.1 "c" & 3 \\
\hline 5 & 5.32 .1 & 3 & 35 & 35.4.5.1 "d" & 3 \\
\hline 5 & 5.32 .2 & 3 & 35 & 35.4.5.1 "e" & 3 \\
\hline 5 & 5.33 & 2 & 35 & 35.4.5.1 "f" & 3 \\
\hline 5 & 5.34 & 2 & 35 & 35.4.5.1 "g" & 3 \\
\hline 5 & 5.36 & 1 & 35 & 35.4.5.1 "h" & 3 \\
\hline
\end{tabular}




\begin{tabular}{|l|c|c|c|c|c|}
\hline 5 & 5.38 & 2 & 35 & 35.4 .5 .1 "i" & 3 \\
\hline 5 & 5.38 .1 & 1 & 35 & 35.4 .5 .1 "j" & 3 \\
\hline 5 & 5.39 & 1 & 35 & 35.4 .5 .1 "k" & 3 \\
\hline 5 & 5.39 .1 & 1 & 35 & 35.4 .5 .1 "l" & 3 \\
\hline 5 & 5.40 "a" & 2 & 35 & $35.4 .5 .1 ~ " m "$ & 3 \\
\hline 5 & 5.40 "b" & 2 & & & \\
\hline
\end{tabular}

Fonte: (Elaborado pelo autor, 2020).

\subsubsection{Consolidação das penalidades}

Para consolidação das penalidades cabíveis, foi utilizada como referência as tabelas presentes no Anexo IA e no Anexo II da NR 28, A atribuição das penalidades leva em consideração a quantidade de funcionários existentes na empresa, no caso, a faixa de 51 a 100 empregados.

Foram consideradas as penalidades envolvendo as categorias "Segurança no Trabalho" e "Medicina do Trabalho". Para identificação dos itens foi elaborada uma planilha correspondente a todos os itens de não conformidades identificadas neste trabalho.

Adotou-se como valor de referência para a UFIR (Unidade de Referência Fiscal) o valor de R\$ 1,0641. Este valor corresponde ao momento de sua extinção por decorrência do §3ㅇ do Art. 29 da Medida Provisória 2095/1976. Desta maneira, obteve-se o total de 73 não conformidades e o valor

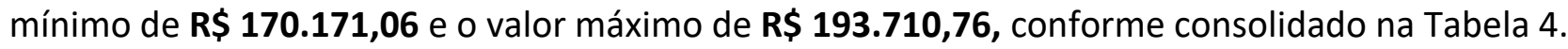

Tabela 3 - Consolidação das multas de segurança do trabalho aplicável

\begin{tabular}{|c|c|c|c|c|c|c|}
\hline \multirow{2}{*}{ Gravidade } & \multirow{2}{*}{ Quant. } & \multirow{2}{*}{ valor min. UFIR } & \multirow{2}{*}{ valor máx. UFIR } & \multirow{2}{*}{ Ufir } & \multicolumn{2}{|c|}{ valores ( R\$) } \\
\cline { 5 - 7 } & & & & & Minímos & Máximos \\
\hline I1 & 13 & 964,00 & 1104,00 & 1,06 & $\mathrm{R} \$ 13.283,92$ & $\mathrm{R} \$ 15.213,12$ \\
\hline $\mathrm{I} 2$ & 29 & 1936,00 & 2200,00 & 1,06 & $\mathrm{R} \$ 59.512,64$ & $\mathrm{R} \$ 67.628,00$ \\
\hline $\mathrm{I} 3$ & 29 & 2899,00 & 3302,00 & 1,06 & $\mathrm{R} \$ 89.115,26$ & $\mathrm{R} \$ 101.503,48$ \\
\hline I4 & 2 & 3877,00 & 4418,00 & 1,06 & $\mathrm{R} \$ 8.219,24$ & $\mathrm{R} \$ 9.366,16$ \\
\hline Total & $\mathbf{7 3}$ & & & & $\mathrm{R} \$ \mathbf{1 7 0 . 1 3 1 , 0 6}$ & $\mathrm{R} \$ \mathbf{1 9 3 . 7 1 0 , 7 6}$ \\
\hline
\end{tabular}

Fonte: (Elaborado pelo autor, 2020).

A NR 28, em seu item 28.3.1.1, determina que caso as ocorrências identificadas por um auditor do MTE não forem sanadas e em nova fiscalização forem identificadas como reincidentes, a penalidade aplicável deixa de corresponder à tabela do anexo I da NR 28 e utiliza como referência para qualquer gravidade os valores apresentados na tabela 5. Estes valores, também, são aplicáveis, nos casos em que há embargo ou resistência à fiscalização, emprego de artifício ou simulação para fraudar a lei. 
Tabela 4 - Multas por Reincidência.

\begin{tabular}{|c|c|}
\hline \multicolumn{2}{|c|}{ VALOR DA MULTA (em UFIR) } \\
\hline Segurança do Trabalho & Medicina do Trabalho \\
\hline 6.304 & 3.782 \\
\hline
\end{tabular}

Fonte: (NR 28)

De forma facilitar a percepção global dos valores de multa e a distribuição da gravidade dos itens descumpridos nas instalações são apresentados o Gráfico 1 e o Gráfico 2. 0 primeiro foi elaborado com base na análise dos dados da Tabela 4 e permite a avaliação da distribuição da gravidade das infrações observadas e a distribuição pela média das penalidades aplicáveis. Já o segundo apresenta a distribuição por gravidade de cada não conformidade existente nas instalações da empresa e deve ser utilizado como uma ferramenta para a priorização das ações corretivas.

Gráfico 1 - Valores em percentuais das penalidades médias

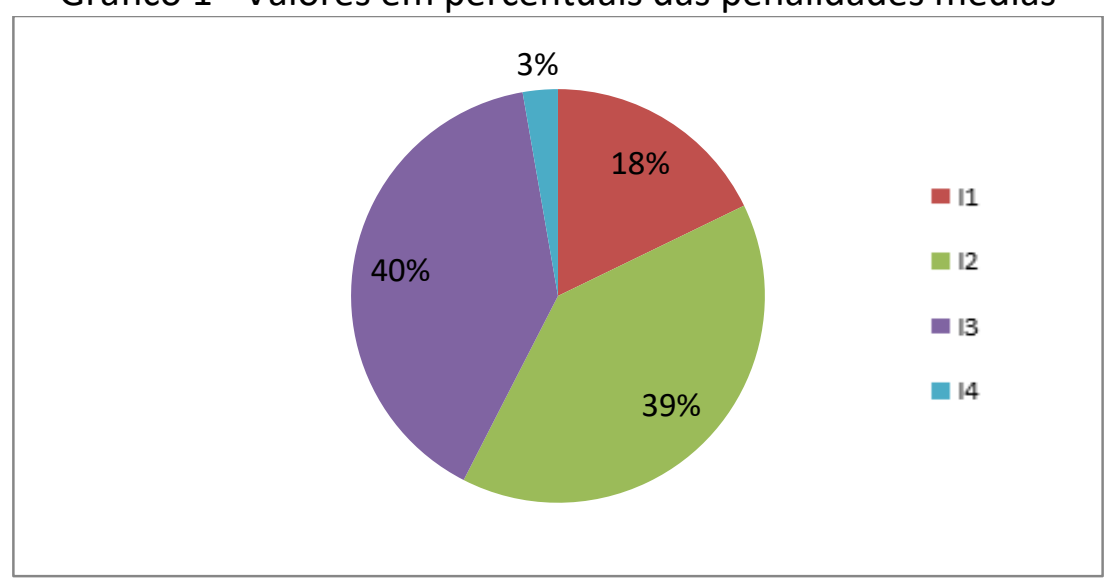

Fonte: (Elaborado pelo autor, 2020)

Gráfico 2 - Distribuição da gravidade dos itens

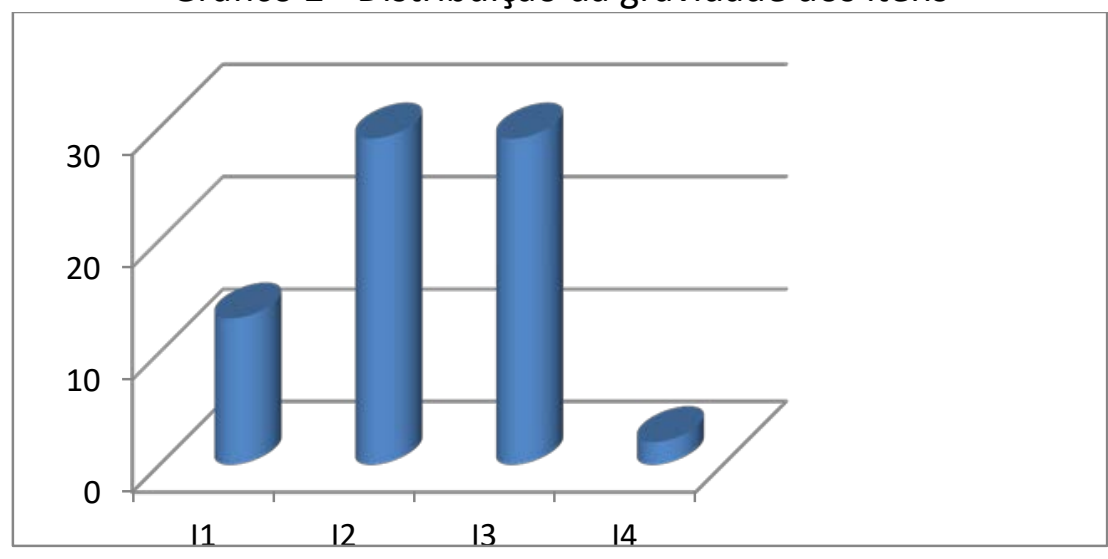

Fonte: (Elaborado pelo autor, 2020)

De forma à facilitar a percepção global dos valores de multa e a distribuição da gravidade dos itens descumpridos nas instalações são apresentados o Gráfico 1 e o Gráfico 2. O primeiro foi 
elaborado com base na análise dos dados da Tabela 4 e permite a avaliação da distribuição da gravidade das infrações observadas e a distribuição pela média das penalidades aplicáveis. Já o segundo apresenta a distribuição por gravidade de cada não conformidade existente nas instalações da empresa e deve ser utilizado como uma ferramenta para a priorização das ações corretivas.

Na Tabela 6 é apresentada uma estimativa do valor da multa por reincidência para a instalação. Por esta tabela, verifica-se que a diferença entre o valor por reincidência e o valor normal máximo de penalidade corresponde a $\mathrm{R} \$ 290.055,94$ apontando a pertinência de eliminar as não conformidades verificadas na empresa.

Tabela 5 - Valor de multa por reincidência.

\begin{tabular}{|l|c|c|c|}
\hline \multirow{2}{*}{ Valor por reincidência } & Total de itens & Valor unitário & Valor total \\
\cline { 2 - 4 } & 73 & $\mathrm{R} \$ 6.304,00$ & $\mathrm{R} \$ 460.192,00$ \\
\hline
\end{tabular}

Fonte: (Elaborado pelo autor, 2020)

\section{CONSIDERAÇÕES FINAIS}

Durante as vistorias realizadas para a realização desse estudo de caso, foi verificado que a MR Engenharia, apesar de estar no mercado há mais de 20 anos, apresenta um recente amadurecimento no setor de segurança. Isto se deve, em parte, ao fato de a empresa ter funcionários registrados no seu quadro apenas a partir dos últimos quatro anos.

Para melhorar a gestão de saúde ocupacional e segurança do trabalho, a empresa deverá alterar sua estrutura organizacional, criando uma Diretoria de HSE. Esta nova diretoria deverá apoiar e suportar as políticas de segurança na empresa, criar procedimentos, executar os programas legais obrigatórios, realizar os DDS além de elaborar um plano de emergência.

A empresa está com um perfil inadequado de atendimento às NR do MTE, embora sua primeira contratação representativa tiver exigido a implementação da maioria das Normas Regulamentadoras através de contrato. Entretanto, foi verificada a existência de diversas não conformidades no seu departamento administrativo e no galpão, demonstrando a falta de cultura da empresa no gerenciamento da saúde ocupacional e segurança do trabalho.

A gestão da manutenção dos equipamentos realizada pela MR Engenharia não atende a diversos padrões definidos nas referências da ABNT e das práticas usuais de mercado. A deficiência 
na gestão de manutenção pode se tornar um elemento que pode favorecer a ocorrência de acidentes pela ausência da definição de medidas de controles de risco de maneira clara.

A CIPA da MR Engenharia não está formada, gerando vulnerabilidade em relação ao atendimento da legislação. Ademais, a inexistência da CIPA representa a perda de uma estrutura que poderia atuar efetivamente na melhoria das condições de segurança nas instalações da empresa. A CIPA deve ser utilizada como apoio as atividades que são definidas aos profissionais do SESMT, desde que seus membros sejam capacitados para desenvolver esta atividade.

Conclui-se que a MR Engenharia deverá ser capaz de concentrar esforços para o atendimento das determinações legais. Além disso, pretende-se que a empresa vislumbre este trabalho como uma referência para a identificação de oportunidades de melhoria das condições de trabalho além dos requisitos legais, confirmando assim o seu compromisso com a melhoria contínua dos processos e serviços.

\section{REFERÊNCIAS BIBLIOGRÁFICAS}

FUNDACENTRO. RTP 4: Escadas, rampas e passarelas. São Paulo: Fundacentro, 2002.

PAMPALON, Gianfranco. Trabalho em Altura Prevenção de Acidentes por Quedas. 2 ed. Ministério do Trabalho e Emprego, São Paulo, 2004.

MATTOS, Ubirajara. Higiene e Segurança do Trabalho, Editora Elsevier.

Ministério do Trabalho e Emprego (MTE). Brasília: MTE, 1978. Disponível em: <http://portal.mte.gov.br/data/files/8A7C816A38CF493C013906EC437E23BF/NR-

10\%20(atualizada).pdf >. Acesso em: 10 abr. 2020.

Ministério do Trabalho e Emprego (MTE). Norma Regulamentadora 1 - Disposições Gerais. Brasília: MTE, $1978 . \quad$ Disponível em: <http://portal.mte.gov.br/data/files/FF8080812BE914E6012BEF0F7810232C/nr_01_at.pdf>. Acesso em: 5 jan. 2020.

Ministério do Trabalho e Emprego (MTE). Norma Regulamentadora 4 - Serviços especializados em engenharia de segurança e em medicina do trabalho. Brasília: MTE, 1978. Disponível em: <http://portal.mte.gov.br/data/files/FF80808145B269620145D2D2CC874DCC/NR04\%20(Atualizada\%202014).pdf>. Acesso em: 5 jan. 2020.

Ministério do Trabalho e Emprego (MTE). Norma Regulamentadora 5 - Comissão interna de prevenção de acidentes. Brasília: MTE, 1978. Disponível em: <http://portal.mte.gov.br/data/files/8A7C812D311909DC0131678641482340/nr_05.pdf>. Acesso em: 5 maio. 2020.

Ministério do Trabalho e Emprego (MTE). Norma Regulamentadora 6 - Equipamento de Proteção Individual - EPI. Brasília: MTE, $1978 . \quad$ Disponível: 
<http://portal.mte.gov.br/data/files/FF8080812DC56F8F012DCDAD35721F50/NR-

06\%20\%28atualizada\%29\%202010.pdf>. Acesso em: 10 abr. 2020.

Ministério do Trabalho e Emprego (MTE). Norma Regulamentadora 18 - Condições e meio ambiente de trabalho na indústria da construção. Brasília: MTE, 1978. Disponível em: <http://portal.mte.gov.br/data/files/FF8080812BE914E6012BEFC3EDA95064/nr_18_01.pdf>.

Acesso em: 16 set. 2019.

Ministério do Trabalho e Emprego (MTE). Norma Regulamentadora 28 - Fiscalização e Penalidades. Brasília: 1978.

Disponível em: <http://portal.mte.gov.br/data/files/FF80808145B269620145D7E3382A5095/NR28\%20(Atualizada\%202014).pdf>. Acesso em: 8 ago. 2019.

Ministério do Trabalho e Emprego (MTE). Norma Regulamentadora 35 - Proteção Contra Incêndios. Brasília: MTE, 1978. Disponível em: <http://portal.mte.gov.br/data/files/8A7C816A2E7311D1012FE5B554845302/nr_23_atualizada_2 011.pdf>. Acesso em: 15 jul. 2019.

UNIVERSIDADE DE SÃO PAULO - USP. Procedimentos de segurança para trabalhos de manutenção. São Paulo: SESMT/USP, 2010. Disponível em: <http://www.usp.br/codage/files/circ015anexo2-drhago-2010.pdf>. Acesso em: 8. jun 2019. 